
Engineering and Technology

(An ISO 3297: 2007 Certified Organization)

Vol. 4, Issue 2, February 2015

\title{
Numerical Optimization of Cold Formed Closed Built-up Steel Column
}

\author{
Pradeep $\mathrm{T}^{1}$, Arun $\mathrm{N}^{1}$ \\ P.G. Student, Department of Civil Engineering, K.S.Rangasamy College of Technology, Tiruchengode, Namakkal \\ Tamil Nadu India ${ }^{1}$
}

\begin{abstract}
The Optimization of cold formed closed steel built-up columns without stiffeners is performed using finite element analysis. An accurate finite element model is used for study in which different size of webs are investigated. The closed cold formed built-up steel column strength were studied with and without coupling of section. The finial section of column buckling behaviour is predicted by the nonlinear finite element method anddiscusses the unfactored design column strength.
\end{abstract}

KEYWORDS: Channel section, Built-up section and Optimized specimen.

\section{INTRODUCTION}

In steel structures, two primary structural steel member types are used: Hot rolled steel members and Cold- forming steel members. The Hot rolled steel members are formed at elevated temperature whereas Cold formed steel are formed at room temperature. The Hot rolled section are heavy weight instead of this, Cold formed steel are less weight. Cross sectional shapes are formed to close tolerances and these can be consistently repeated for as long as required. Cold rolling can be employed to produce almost any desired shape to any desired length. It is possible to displace the material far away from the neutral axis in order to enhance the load carrying capacity.

Cold-formed steel sections are widely used in construction and building industries. The popularity of these products has dramatically increased in recent years due to their wide range of application, ease of fabrication and high strength-toweight ratios. Cold-formed steel structural members may lead to a more economic design than hot-rolled steel members. Cold-formed steel members are either cold-rolled or brake-pressed into structural shapes. Channel section is a common type of Singly-symmetric section. Cold-formed steel channels are commonly used as wall studs and chord members of roof trusses in steel frame housing and industrial buildings. These structural members are mainly subjected to axial compression. The compression members may fail in complex buckling modes, such as local, distortional, flexural and flexural-torsional buckling.

\section{NUMERICAL INVESTIGATION}

The main scope of the study is as follows:

- To examine the effect of strength in cross sectional geometries on thecold-formed steel built-up section by using the finite element analysis software ANSYS 12.

- $\quad$ To choose the Best channel closed built-up section.

\section{SELECTION OF SECTION}

The length of the section is chosen in the range where the Torsional buckling occurs in the elastic buckling analysis using CUFSM software. All the section having the length of $1000 \mathrm{~mm}$ and thickness of $1.6 \mathrm{~mm}$. The Dimensions of section is initially chosen from thumb rule of relation between web $(\mathrm{W})$ and flange $(\mathrm{F})$ element $(\mathrm{W}=2 \mathrm{~F})$. The cross section geometries and dimensions are shown in Figure.01. 


\section{International Journal of Innovative Research in Science, Engineering and Technology}

(An ISO 3297: 2007 Certified Organization)

Vol. 4, Issue 2, February 2015

Table 01. Specimen Dimensions

\begin{tabular}{|c|c|c|c|c|c|c|}
\hline \multirow[b]{2}{*}{ Specimen } & \multirow{2}{*}{$\begin{array}{l}\text { Gross } \\
\text { Area } \\
\text { (Sq.mm) } \\
\text { for } \\
\text { Channel }\end{array}$} & \multirow{2}{*}{$\begin{array}{l}\text { Gross Area } \\
\text { (Sq.mm) } \\
\text { for } \\
\text { Built-up }\end{array}$} & \multicolumn{4}{|c|}{ Specimen Dimensions (mm) } \\
\hline & & & $\mathbf{W}$ & $\mathbf{F}$ & $\mathbf{L}$ & $\mathbf{t}$ \\
\hline \multirow{9}{*}{ 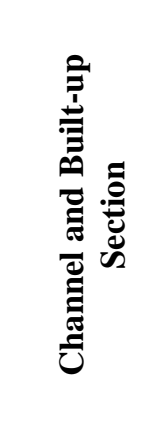 } & 315 & 630 & 100 & 50 & 1000 & 1.6 \\
\hline & 299 & 598 & 90 & 50 & 1000 & 1.6 \\
\hline & 283 & 566 & 80 & 50 & 1000 & 1.6 \\
\hline & 267 & 534 & 70 & 50 & 1000 & 1.6 \\
\hline & 251 & 502 & 60 & 50 & 1000 & 1.6 \\
\hline & 235 & 470 & 50 & 50 & 1000 & 1.6 \\
\hline & 219 & 438 & 40 & 50 & 1000 & 1.6 \\
\hline & 203 & 406 & 30 & 50 & 1000 & 1.6 \\
\hline & 195 & 390 & 25 & 50 & 1000 & 1.6 \\
\hline
\end{tabular}

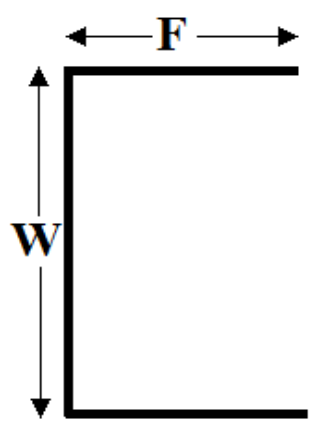

(a) Channel section

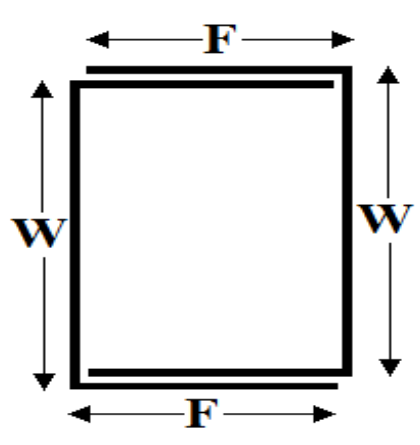

(b) Built-up section

Figure 01. Section Geometries

The Torsional strength of column are identified using linear Finite element analysis software (CUFSM). The figure 02 shows the curve for load factor and length of the section. The torsional failure is occur in $1000 \mathrm{~mm}$ of the length , this is the problem to rectified.

CUFSM results - BASIS:CFSM analysis is off NORM:vector norm

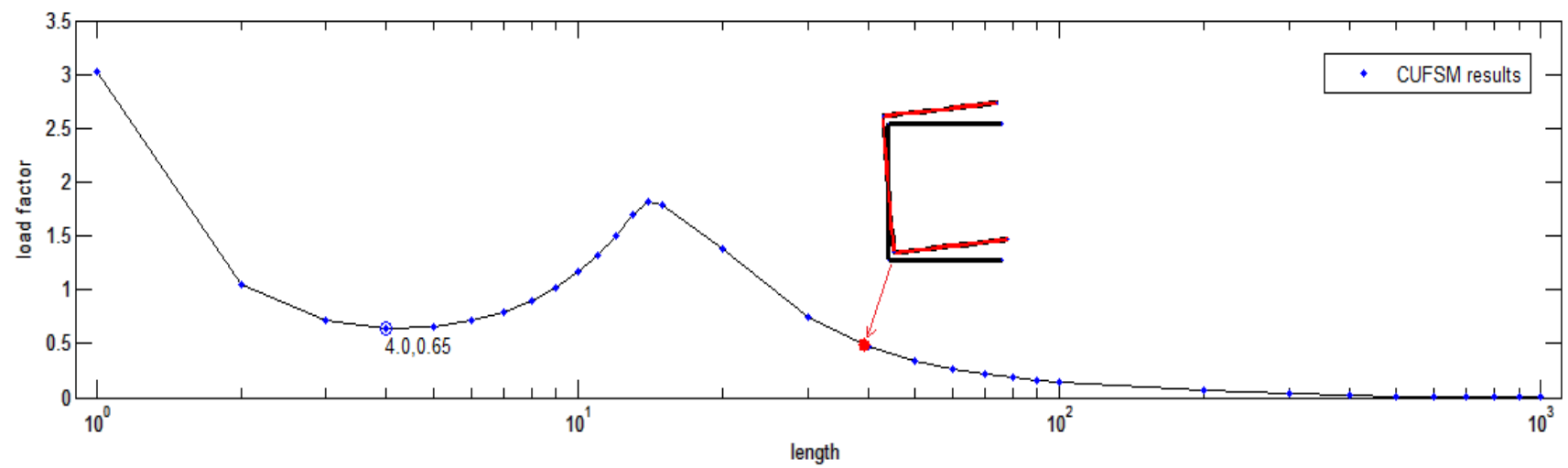

Figure 02. Length from CUFSM result 


\title{
International Journal of Innovative Research in Science, Engineering and Technology
}

\author{
(An ISO 3297: 2007 Certified Organization)
}

\section{Vol. 4, Issue 2, February 2015}

IV.

FINITE ELEMENT MODEL

Finite element analysis plays an important role in engineering practice, as it is relatively in expensive and time efficient compared with physical experiments, especially in parametric study of cross section geometry is involved. Finite element analysis software package ANSYS 12 is used to simulate the buckling behaviour of the intermediate length cold-formed steel cold-formed steel stiffened sigma section under axial compression. Four-noded SHELL 181 elements are used in the finite element analysis. Material and geometric nonlinearity are incorporated in the developed finite element model whereas residual stresses and cold-forming effects are not included in the finite element model. The models are based on the centre line cross section dimensions. A series of mesh convergences studies are carried out, a mesh size of $10 \mathrm{~mm} \mathrm{X} 10 \mathrm{~mm}$ are found to be suitable for the column length of $1000 \mathrm{~mm}$. The Detailed Finite element model including mesh size and support conditions are illustrated in Figure 03.

In this study pin end conditions are used as shown in Figure 03(c) to Figure 03(d). At the unloaded end, translations in all the directions are restrained as well as the rotation about the longitudinal direction. But in the loaded end is restrained as same as that of the unloaded end except for the translation in the longitudinal direction. All the boundary conditions are applied to the independent centroidal node of the rigid fixed point created at the loaded and unloaded end of the model defined as the master nodes .This master node acts as a rigid surface that was rigidly connected to both ends of the column as shown in Figure 1d. All the sections are of thickness $1.6 \mathrm{~mm}$ with yield stress of 270 $\mathrm{N} / \mathrm{mm}^{2}$, Young s modulus of $2 \times 10^{5} \mathrm{~N} / \mathrm{mm}^{2}$ and Tangent modulus of $20000 \mathrm{~N} / \mathrm{mm}^{2}$ with a Poisson's ration of 0.3 . The local-distortional imperfection is taken as approximately equal to the plate thickness as recommended by Schafer and Pekoz.

Two types of analyses are used in the finite element analysis for buckling. Initially a linear elastic buckling analysis is performed to obtain the buckling loads and associated buckling modes. Finally, non linear buckling analyses are performed to predict the ultimate load capacity.

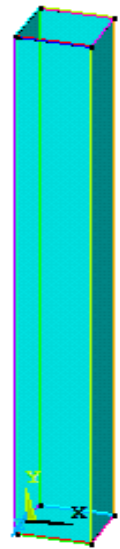

(a) Longitudinal View

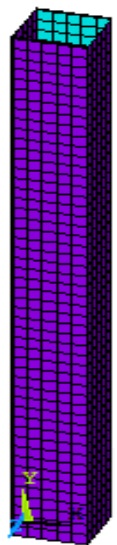

(b) Meshed Model

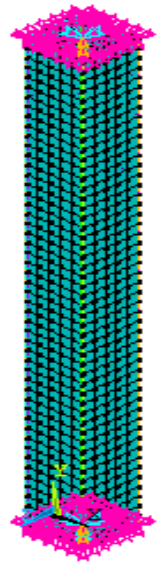

(c) Finite Element

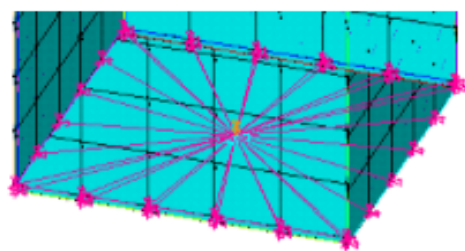

Bottom End Model

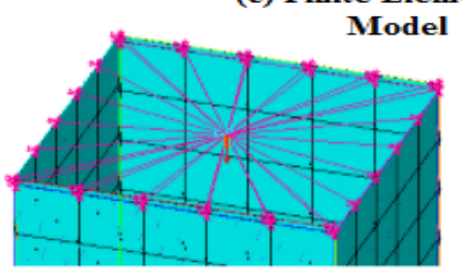

Top End

(d) Rigid Region

Figure 03. Details of finite element model 


\section{International Journal of Innovative Research in Science, Engineering and Technology}

\section{(An ISO 3297: 2007 Certified Organization) \\ Vol. 4, Issue 2, February 2015 \\ V. NUMERICAl RESUlts AND DiscuSSION}

Cold formed steel section of suitable dimension is generated in the analysis software ANSYS 12. The Non-linear Load and Deflection for all the sections were predicted from finite element analysis software (ANSYS 12). The investigation is carried out by developing the model of the order of the relation between web (W) and flange ( $F),(W=2 F$ to $F=2 W)$. The same study was carried in the closed built-up steel channel column. The Load and Deflection of each section of both open channel and closed built-up channel where shown in Table 02.

Table 02. Load and Deflection of Sections

\begin{tabular}{|c|c|c|c|c|c|c|c|c|}
\hline Specimen & $\begin{array}{c}\text { Depth } \\
(\mathrm{W}) \text { in } \\
\text { mm }\end{array}$ & $\begin{array}{c}\text { Load } \\
(\mathbf{P}) \text { in } \\
\text { Kn }\end{array}$ & $\begin{array}{l}\text { Deflection } \\
\text { (Y) in } \mathbf{m m}\end{array}$ & Specimen & $\begin{array}{c}\text { Load } \\
(\mathbf{P}) \text { in } \\
\text { Kn }\end{array}$ & $\begin{array}{l}\text { Deflection } \\
(\mathrm{Y}) \text { in } \mathrm{mm}\end{array}$ & $\frac{\mathbf{P}_{\mathrm{b}}}{\mathbf{P}_{\mathrm{c}}}$ & $\frac{\mathbf{Y}_{b}}{\mathbf{Y}_{\mathbf{c}}}$ \\
\hline \multirow{9}{*}{ 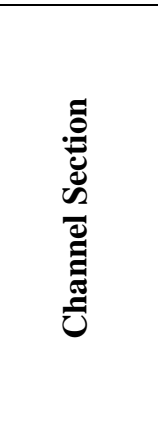 } & 100 & 27.925 & 1.392 & \multirow{9}{*}{ 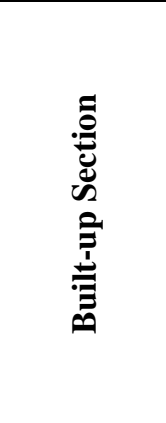 } & 87.607 & 0.928 & 3.137225 & 0.666667 \\
\hline & 90 & 26.435 & 1.395 & & 87.907 & 0.947 & 3.325402 & 0.678853 \\
\hline & 80 & 24.611 & 1.398 & & 86.477 & 0.978 & 3.513754 & 0.699571 \\
\hline & 70 & 23.284 & 1.299 & & 84.976 & 1.003 & 3.649545 & 0.772132 \\
\hline & 60 & 21.978 & 1.327 & & 82.547 & 1.0378 & 3.755892 & 0.782065 \\
\hline & 50 & 21.015 & 1.3768 & & 79.69 & 0.1151 & 3.792053 & 0.0836 \\
\hline & 40 & 19.397 & 1.445 & & 69.849 & 1.1518 & 3.601021 & 0.797093 \\
\hline & 30 & 20.292 & 0.8689 & & 43.91 & 0.8871 & 2.163907 & 1.020946 \\
\hline & 25 & 14.637 & 0.9726 & & 33.515 & 0.678 & 2.289745 & 0.697101 \\
\hline
\end{tabular}

The Nonlinear analysis model were developed for all the sections, which were optimized form graph. The graph were drawn from the table 02, in the $\mathrm{X}$ axis have depth of section and $\mathrm{Y}$ axis have Load and Deflection ratio of built-up to channel sections as shown in figure 04. The optimized closed built-up section have good strength and less deflection are shown in graph, the depth of section having $50 \mathrm{mmX} 50 \mathrm{~mm}(\mathrm{~W}=\mathrm{F})$. The nonlinear finite element model were developed for optimized closed built-up section are shown in figure 05 in different manner. And the optimized section were compared with placing of open section in different manner.

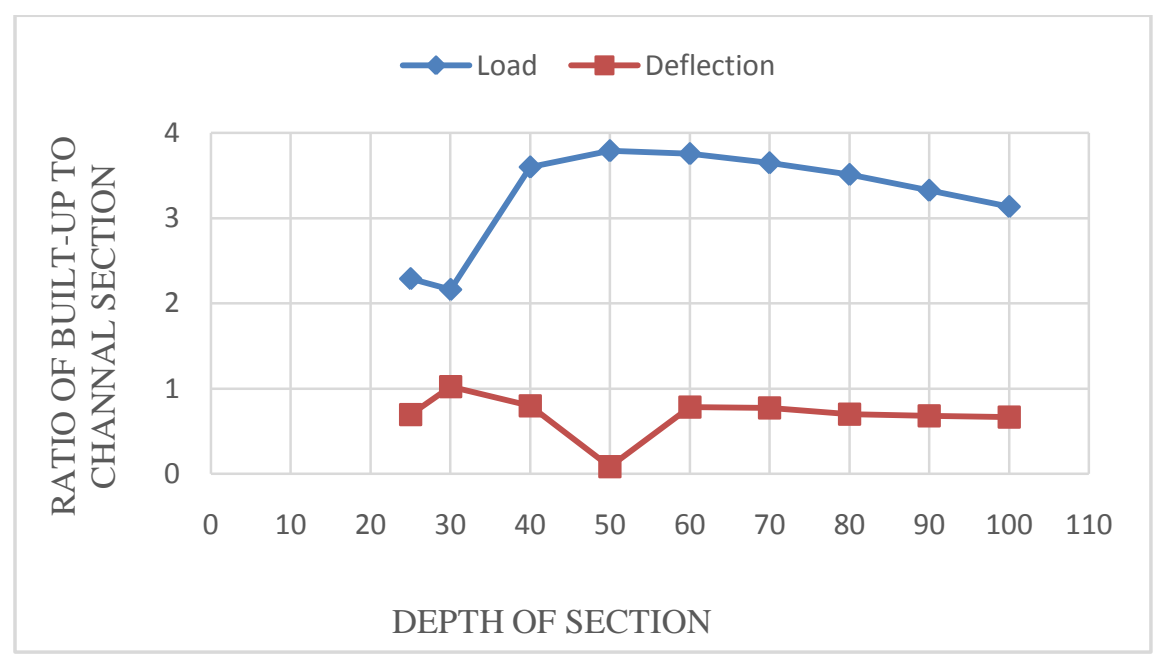

Figure 04. Depth vs. Load and Deflection ratio 


\section{International Journal of Innovative Research in Science, Engineering and Technology}

(An ISO 3297: 2007 Certified Organization)

Vol. 4, Issue 2, February 2015

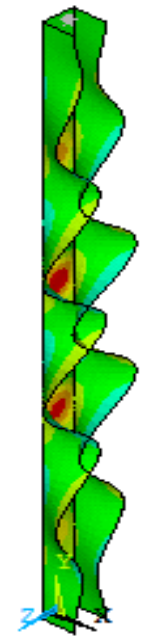

(a)
Channel section

Figure 05. Behaviours of Sections

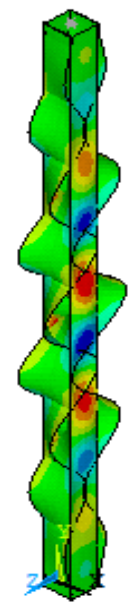

(b) Built-up section

\section{CONCLUSION}

Finite element analysis of the cold formed closed built-up column member is analysed using ANSYS 12 software. The nonlinear strength and deflections were predicted from above research, for each cross sections and developed the relations between the built-up and channel sections. The sections were optimised from the finite element result. Finally the section had been confirmed and the behaviour of both the sections have been studied.

\section{REFERENCES}

1. Ben Young, "Research on cold-formed steel columns", Thin-Walled Structures Vol; 46 pp,731-740, 2008.

2. Teng, J.G., Yao J, Y. Zhao, "Distortional buckling of channel beam-columns", Thin-Walled Structures Vol; 41pp, 595-617, 2003.

3. Beregszaszi Z, Adany S, "Application of the constrained finite strip method for the buckling design of cold-formed steel columns and beams via the direct strength method", Journal of Computers and Structures,Vol; 89, pp.2020-2027,2011.

4. Narayanan S, Mahendran M, "Ultimate capacity of innovative cold-formed steel columns. Journal of Constructional Steel Research", Vol; 59, pp,489-508, 2003.

5. Nguyen V.B., Wang C.J., Mynors D.J., English M A, Castellucci M A, "Compression tests of cold-formed plain and dimpled steel columns" Journal of Constructional Steel Research Vol; 69,pp,20-29, 2012.

6. Shanmugam N.E., Dhanalakshmi M., "Design for openings in cold-formed steel channel stub columns", Thin-Walled Structures, Vol; 39, pp, 961-981,2001.

7. Alia M.AL., Tomkoa M., Demjana I., Kvočáka V., "Thin-walled cold-formed compressed steel members and the problem of initial imperfections", Steel Structures and Bridges Vol; 40, pp,8-13,2012.

8. BatistaE. M. andRodriguesF. C., "Buckling Curve for Cold-Formed Compressed Members", Journal of Constructional steel research, Vol.28, pp.121-136, 1994.

9. SchaferB.W. and Peko“z T., "Computational modeling of cold-formed steel: characterizing geometric imperfections and residual stresses", Journal of Constructional steel research, Vol.47, pp.193-210, 1998.

10. Ben Young., "Design of channel columns with inclined edge stiffeners", Journal of Constructional Steel Research, Vol.60, pp. 183-197, 2004.

11. Jintang Yan and Ben Young "Numerical investigation of channel columns with complex stiffeners-part I: test verification", Thin-Walled Structures, Vol.42, pp.883-893, 2004.

12. Ben Young and Jintang Yan "Numerical investigation of channel columns with complex stiffeners-part II: parametric study and design”,Thin-Walled Structures, Vol.42, pp.895-909, 2004. 